\title{
TEMPORAL VARIABILITY OF LONGITUDINAL SEDIMENT TRANSPORT ON THE BRAZILIAN CONTINENTAL SHELF
}

\author{
T. B. Trombetta, \\ W. C. Marques, \\ P. H. Oleinik, \\ R. C. Guimarães, \\ T. F. Leal, \\ A. R. Bendô, \\ B. V. Lopes, \\ and E. P. Kirinus \\ Universidade Federal do Rio Grande - FURG \\ Laboratório de Análise Numérica e Sistemas \\ Dinâmicos - LANSD \\ Instituto de Matemática, Estatística e \\ Física - IMEF \\ Av. Itália, km 8, Campus Carreiros, \\ CEP 96203-000, Rio Grande, Rio Grande do \\ Sul, Brasil \\ thaisabtrombetta@gmail.com \\ wilianmarques47@gmail.com \\ phe.h.o1@gmail.com \\ ricardo_guimaraes@hotmail.com.br \\ thalitaeinstein-fisica@hotmail.com \\ rayltonbendo@gmail.com \\ lopesbruno13@gmail.com \\ ekirinus@gmail.com

\section{ABSTRACT} \\ The sediment transported along the coast can alter the existing balance in \\ certain environments, causing or accelerating erosive processes, and \\ resulting in economic and environmental damages. In this way, predicting \\ changes in the coastal zone and understanding the beach processes is an \\ essential source of information for the elaboration of coastal management \\ plans. In this context, the present work aims to estimate the alongshore \\ sediment transport (LST) in several sectors of the Brazilian Coast, \\ identifying the annual average and the predominant transport. This study \\ was conducted for the period between the years 1979 and 2015, using \\ computational modeling to investigate the behavior of the waves, and \\ empirical formulas to calculate the LST rates. In addition, the temporal \\ variability was investigated through the wavelet analysis. The results \\ showed a great diversity in the wave climate behavior along the Brazilian \\ Coast, presenting a good correlation in terms of magnitude between the \\ estimation of LST and past studies in the different sectors analyzed. The \\ place where transport has become pronounced understands the sector \\ between Alagoas and Rio Grande do Norte states, while the opposite was \\ observed in the Southern part of Bahia. The wavelet analysis showed that \\ the spectrum of LST time series has a significant amount of energy for \\ processes with a seasonal and annual variability, indicating that the northern \\ regions of Brazil are most affected by the interannual processes. In this \\ sense, informations along the Brazilian coast are presented, that may be \\ considered in future projects, involving the sustainable management of the \\ coastal zones. \\ Keywords: coastal zone; numerical modeling; TOMAWAC; waves; \\ sediment transport \\ Received: February 27, 2019 \\ Revised: March 19, 2019 \\ Accepted: March 30, 2019
}

\section{NOMENCLATURE}

CERC Coastal Engineering Research Center

$\mathrm{D}_{50}$ average diameter of the sediments, $\mathrm{mm}$

Dp average direction at the peak, ${ }^{\circ}$

Hs significant wave height, $\mathrm{m}$

K dimensionless parameter

LST longshore sediment transport

P PNBOIA

Tp peak period, $\mathrm{s}$

T TOMAWAC

\section{INTRODUCTION}

The waves play a substantial role in coastal modeling, influencing the coastal features, so that waves vary morphologically at different temporal and spatial scales (Holthuijsen, 2007). According to Klein et al. (2006), the sandy beaches present their own dynamics due to the mobility of the sediments, transported by effects of the waves, coastal currents, tides and winds, resulting in processes of accretion and erosion. The wave climate is the main variable that induces medium and short-term coastal processes, responsible for transport in the longitudinal and transverse directions of the coastline (Muehe and Corrêa, 1989).

Inserted in this context, the present study aims to estimate the longshore sediment transport (LST) in different sectors of the Brazilian coast, identifying the annual averages and the dominant direction of transport. For this reason, the wave climate in the entire region of study was analyzed using computational modeling of waves, in addition to LST which was calculated using the models proposed by the Coastal Engineering Research Center (CERC, 1984) and by Kamphuis (1991). The formula that best applies in each region was also defined, by comparing the results of previus studies related to morphodynamic processes. In order to conclude the LST evaluation, temporal variability was investigated through the wavelet analysis, following the 
methodology proposed by Torrence and Compo (1998) and rectified by Liu et al. (2007) and Veleda et al. (2012).

The study area covers the whole Brazilian continental shelf, extending between the latitudes $4^{\circ}$ North until $34^{\circ}$ South. For the sedimentological characterization of the study region, and to identify the average diameter of the sediments $\left(D_{50}\right)$, a division of the Brazil coast into four distinct sections was performed, based on the analysis of the sedimentological chart derived from ReviZEE Program expeditions data and prepared by the Diretoria de Hidrografia e Navegação (DHN).

\section{MATERIALS AND METHODS}

This study addresses the application of the third generation wave model TOMAWAC (TELEMACBased Operational Model Addressing Wave Action Computation) to simulate the sea state on the Brazilian Continental Shelf over a period of 37 years, between 1979 and 2015, with daily step for saving results. The spatial domain is represented by an unstructured mesh, Fig. 1, composed of 547479 nodes with varying relative distance between them (from $55 \mathrm{~km}$ near the oceanic boundary to $1 \mathrm{~km}$ on the coastline).

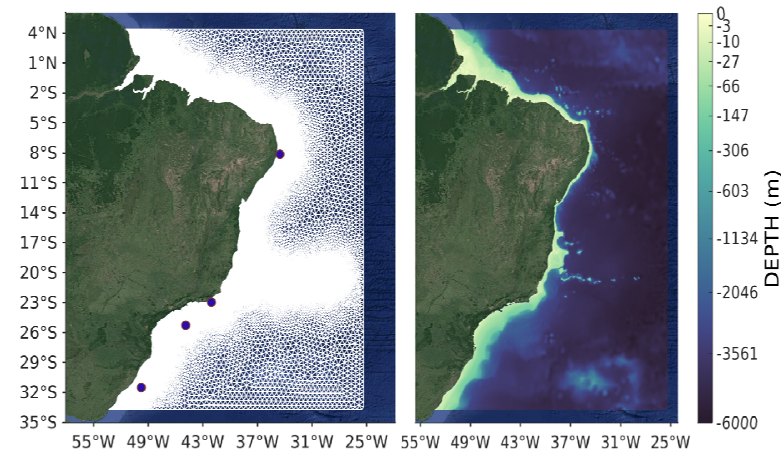

Figure 1. Illustrative images of the discretization of the computational domain (a) and bathymetry used in the studied region (b). The points in blue represent the areas validated.

\section{NUMERICAL MODEL}

The numerical model TOMAWAC was used to perform the simulations. This model is part of the open TELEMAC-MASCARET modeling system (www.opentelemac.org). To perform the numerical simulations, TOMAWAC was initialized from the rest. The oceanic boundaries were set by the imposition of significant wave height (Hs), peak period (Tp) and average direction at the peak (Dp), downloaded from the database generated by the wave forecasting model ERA Interim (www.ecmwf.int) by ECMWF (European Center for Medium-Range Weather Forecasts). The superficial boundary was forced by winds from ERA Interim with spatial resolution of $0.75^{\circ}$ and temporal resolution of $6 \mathrm{~h}$.

\section{LONGSHORE SEDIMENT TRANSPORT RATE}

The calculation of LST rate is based in equations that was developed and calibrated over the years by different authors. In this study, LST was estimated with wave's parameters and sedimentary characteristics of each part of the study region, being used the formulas proposed by CERC (1984) and Kamphuis (1991).

The coefficient $\mathrm{K}$ value, in the formula proposed by CERC (1984), was recommended equal 0.39 by the Shore Protection Manual for the United States beaches studied. However, the expression becomes more reliable if the coefficient is calibrated with characteristic data of each region. In this study, the coefficient $\mathrm{K}$ was calculated using the formulations of Kamphuis et al. (1986), del Valle et al. (1994) and Mil-Homens et al. (2013), besides the constant value proposed by the CERC (1984).

\section{VALIDATION}

The use of TOMAWAC on the Brazilian Continental Shelf was validated through the comparison of Hs time series from the model with the same parameter measured by wave buoys over the study region, between the years 2011 to 2015 .

The data used were measured by Programa Nacional de Boias (PNBOIA), and the buoys are located in the coast of Rio Grande - Rio Grande do Sul state, Santos - São Paulo state, Cabo Frio - Rio de Janeiro state and Recife - Pernambuco state. The location is shown in Fig. 1 (a).

To quantify the comparison, different error metrics previously used in similar works (Hallak and Pereira, 2011; Teegavarapu, 2012) were tested. The RMSE expresses magnitude of the error in module of the model, and the Bias measures the mean deviation between the modeled and the buoy data. Tab. 1 shows the computed values of the parameters for Rio Grande (RG), Santos (SA), Cabo Frio (CF) and Recife (RE), comparing the data of TOMAWAC (T) and PNBOIA (P).

Table 1. Statistical parameters calculated comparing TOMAWAC output and buoy data.

\begin{tabular}{|c|c|c|c|c|c|c|c|c|}
\hline & \multicolumn{2}{|c|}{ RG } & \multicolumn{2}{c|}{ SA } & \multicolumn{2}{c|}{ CF } & \multicolumn{2}{|c|}{ RE } \\
\hline Parameter & T & P & T & P & T & P & T & P \\
\hline Hs (m) & 2.38 & 2.36 & 1.63 & 1.95 & 1.15 & 1.35 & 1.64 & 1.61 \\
\hline RMSE & \multicolumn{2}{|c|}{0.80} & \multicolumn{2}{|c|}{0.59} & \multicolumn{2}{|c|}{0.51} & \multicolumn{2}{c|}{0.29} \\
\hline Bias & \multicolumn{2}{|c|}{0.0054} & \multicolumn{2}{|c|}{0.3323} & 0.1959 & -0.0421 \\
\hline
\end{tabular}

The closer to zero Bias values shows that the model does not tend to under or overestimate the model in comparison to the observed data. The RMSE values showed that the differences of the compared data is considerable acceptable, because the difference between the model and the buoy data is squared, what would cause higher RMSE values. 
For the validation of the LST calculation, the formulations proposed by CERC (1984) and by Kamphuis (1991) were applied to different beaches of the southern, southeastern and northeastern Brazilian coast, and compared to the previous studies related to its thematic topic (Tab. 2).

Table 2. Longshore Sediment Transport Rate $\left(10^{6} \mathrm{~m}^{3}\right.$.year $\left.{ }^{-1}\right)$. The negative values indicate the direction of transport southwards.

\begin{tabular}{|c|c|c|c|c|c|}
\hline & \multicolumn{3}{|c|}{ CERC (1984) } & \multirow[b]{2}{*}{$\begin{array}{c}\text { Kamphuis } \\
\text { (1991) }\end{array}$} & \multirow[b]{2}{*}{$\begin{array}{c}\text { Previous } \\
\text { Studies }\end{array}$} \\
\hline Area & 0.39 & $\begin{array}{c}\text { Kamphui } \\
\text { et al. } \\
\text { (1986) }\end{array}$ & $\begin{array}{c}\text { Mil- } \\
\text { Homens } \\
\text { et al. } \\
(2003)\end{array}$ & & \\
\hline Cibratel & -1.654 & -0.356 & -0.297 & -0.521 & -0.400 \\
\hline Natal & 0.698 & 0.026 & 0.099 & 0.084 & 0.587 \\
\hline Galinhos & 0.662 & 0.020 & 0.099 & 0.044 & 0.185 \\
\hline
\end{tabular}

As shown, del Valle et al. (1993) formula was not applied in any of the points in Tab. 2 because it is only suitable for regions with diameters between 0.44 and $1.5 \mathrm{~mm}$.

In relation to the Southeast Region, on the coast of São Paulo state, the sediment transport was validated in the Cibratel Beach based on the result proximity provided by the formula of CERC (1984), with the parameter $\mathrm{K}$ calibrated by Kamphuis et al. (1986), in relation to the study of Araújo and Alfredini (2001). The values of transport resulted in

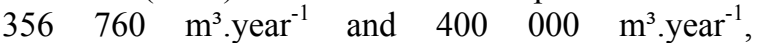
respectively, being considered with similar orders of magnitude, although the authors used another methodology for the study, with different values for the average diameter of sediments and wave data of a measuring period of only 3 years. In addition, the transport direction from North to South validated the analyzed site.

For the Northeast region, in Natal - Rio Grande do Norte state, the LST rates resulted in 698830 $\mathrm{m}^{3}$.year ${ }^{-1}$, considering the formula of CERC (1984) resulted in dominant transport to the North. This site was compared to the study of Araújo (2015), which showed rates of transport of approximately 587211 $\mathrm{m}^{3}$.year ${ }^{-1}$, with net direction towards South-North, giving the validity of the data obtained.

Finally, in the municipality of Galinhos, in Rio Grande do Norte state, the rates of LST resulted in similar order of magnitude, being the formulation proposed by CERC (1984), with the parameter K calibrated by Mil-Homens et al. (2013), with 99042 $\mathrm{m}^{3}$.year 1 , the closer related to the study of the Marcelino et al. (2018), with $185839 \mathrm{~m}^{3}$.year ${ }^{-1}$. This author considered a period of 60 years data, which explains the results equivalence, despite the model applied in the study being different. The dominant transport directed to East-West was also validated.

Thus, for the present study, the LST was calculated in sections all along the Brazilian coast, being considered a specific methodology for each interval, with the corresponding diameter of sediments, as defined previously. Generally, the calculated results showed similarities with respect to magnitude orders of average annual transport in addition to the littoral drift.

\section{RESULTS AND DISCUSSION}

The results presented in this section are derived from a simulation of waves generated by the wind, with 37 years duration, between 1979 and 2015 . Initially, the results obtained are presented in the form of mean fields for the variables of significant height, peak period and angle of incidence of waves, calculated for the whole region of study. These parameters of wave were subsequently used in the calculation of LST and, in order to complete the wave climate evaluation, spatio-temporal variability was investigated through the wavelet analysis, following the methodology proposed by Torrence and Compo (1998) and rectified by Liu et al. (2007) and Veleda et al. (2012).

Through the results it was found that the highest averages of significant wave height occur in the Southeast Region to the Brazilian southern, where the values reaches $2 \mathrm{~m}$. In the sector between Santa Catarina and Rio de Janeiro states, is observed a reduction in the significant wave height for $1.4 \mathrm{~m}$. These findings are in agreement with the studies conducted by Araújo et al. (2003) and Contestabile et al. (2015) on Santa Catarina Island, and by Oleinik et al. (2017) in the Southern-Southeast Brazilian Shelf. Tessler and Goya (2005) also stated that the waves in the southern and southeastern range in an average height of 1 to $4 \mathrm{~m}$, with average period of 10 to $16 \mathrm{~s}$.

In the regions that comprise the North and Northeast of Brazil, it was possible to observe lower values in relation to the South, where the significant wave height average reaches approximately $1 \mathrm{~m}$ e $1: 4 \mathrm{~m}$, respectively. An exception occurs in the vicinity of the Cabo São Roque, where it is possible to identify waves with significant height until $1.6 \mathrm{~m}$. Silva et al. (2000) calculated the wave parameters, in Fortaleza, Ceará, and observed that the significant wave height varies from 1 to $1.5 \mathrm{~m}$, which agrees with the results presented in this study.

In relation to the average wave peak period in the region of study, it was observed a great similarity along the entire Brazilian shelf, with values close to 9.5 s. In the Rio Grande do Sul state and in the southern coast of Bahia, it is noticeable a reduction in wave period as the waves approaches the coast, ranging from $9 \mathrm{~s}$ a $6 \mathrm{~s}$. In the north regions, the average periods of waves are particularly lower than in other regions, reaching maximum $8 \mathrm{~s}$ and decreasing to $7 \mathrm{~s}$ near the coast.

These results are similar to the study of Pianca et al. (2010), who analyzed the climate of waves in the region off the Brazilian coast, as well as, Araújo et al. (2003) and Contestabile et al. (2015) in the Santa Catarina Island, and also Araújo and Alfredini 
(2001) in São Paulo coast. In addition, they allow a conjecture of the action of the winds in the different areas, being that the waves derived from distant storms, have longer periods and can be classified as Swell, while the waves generated by effect of local winds blowing over the sea, have shorter periods and are called Sea.

Regarding the LST, some sites in the Brazilian coast were chosen to the calculation, considering a specific methodology for each region, with the corresponding diameter of sediments, as shown in Tab. 3. It is valid to emphasize that due to the proximity of the regions north and south of Brazil to the boundary conditions of the numerical model, these regions where excluded to the analysis of this study.

Table 3. Representation of LST rates $\left(10^{6} \mathrm{~m}^{3} \cdot\right.$ year $\left.^{-1}\right)$.

\begin{tabular}{|c|c|c|c|}
\hline $\mathrm{D}_{50}$ & Area & LST & Methodology \\
\hline \multirow{6}{*}{2} & Itarema $-\mathrm{CE}$ & 0.198 & \multirow{3}{*}{$\begin{array}{c}\text { CERC } \\
(1984) \\
\text { K by Mil- } \\
\text { Homens et }\end{array}$} \\
\hline & Fortaleza - CE & 0.442 & \\
\hline & Touros - RN & 0.405 & \\
\hline & Cabedelo - PB & 0.485 & \multirow{3}{*}{$\begin{array}{l}\text { CERC } \\
(1984)\end{array}$} \\
\hline & Ilha de Itamaracá - PE & 0.213 & \\
\hline & Maceió - AL & 0.954 & \\
\hline \multirow{7}{*}{0.6} & Aracaju - SE & -0.528 & \multirow{7}{*}{$\begin{array}{c}\text { CERC } \\
(1984) \\
\text { K by del } \\
\text { Valle et al. } \\
(1994)\end{array}$} \\
\hline & Salvador - BA & -0.344 & \\
\hline & Ilhéus - BA & 0.637 & \\
\hline & Canavieiras - BA & 0.310 & \\
\hline & Belmonte - BA & -0.010 & \\
\hline & Vila Velha - ES & -0.340 & \\
\hline & Farol de São Tomé - RJ & -0.257 & \\
\hline \multirow{3}{*}{0.06} & Saquarema - RJ & 0.253 & \multirow{3}{*}{$\begin{array}{c}\text { CERC } \\
(1984) \\
\text { K by } \\
\text { Kamphuis et }\end{array}$} \\
\hline & Suarão - SP & -0.461 & \\
\hline & São Franc. do Sul - SC & 0.394 & \\
\hline
\end{tabular}

The mean liquid sediment transport behavior, in the 37 years simulated, can be explained due the wave climate, which is the main variable in the medium and short term coastal processes.

In the coastal sector between the North coast of Santa Catarina state towards Cabo Frio - Rio de Janeiro, the mean diameter of sediments was considered $0.06 \mathrm{~mm}$, corresponding to a fine sand/muddy-sand, and the methodology proposed by CERC (1984), with the coefficient K calibrated by Kamphuis et al. (1986) was applied.

Already in the segment between Cabo Frio and Aracaju - Sergipe, it was considered a medium sand, with $0.6 \mathrm{~mm}$, and the CERC (1984) formula, with K calibrated by del Valle et al. (1993). Between Aracaju to Cabo de São Roque - Rio Grande do Norte, it was considered the coefficient $\mathrm{K}$ equal to 0.39 for the CERC (1984) formula, while in Cabo de São Roque to Parnaíba - Piauí, the coefficient $\mathrm{K}$ was calibrated by Mil-Homens et al. (2013). In these latter sectors were considered a more coarse sand with $2 \mathrm{~mm}$.

The waves that reach the South and Southeast coast have incidence from Southeast. In addition, according to Pianca et al. (2010), these region receive high waves generated by storms in the South Atlantic, with more energetic waves originated from the South and Southeast, which confirm the direction resulting from the transport of sediments to the Northeast.

A exception occurs in São Paulo littoral, where it is observed that the transport has dominant direction for Southwest which could be explained by the São Paulo coastline being directed NortheastSoutheast, and with dominance of the South Atlantic Tropical Cyclone (generating waves of Northeast and East), in accordance with the study of Araújo and Alfredini (2001).

For the area that surrounds the center-north of the Southeast Region and the South of Bahia presents waves from East and Northeast, thus explaining derive towards South. Tessler and Goya (2005) affirmed that most effective waves in the sediment transport in these regions are predominantly generated by the Trade winds of the Northeast and East quadrants, according to these results.

In the coastal segment of Belmonte and Aracaju, also is observed this behavior. In addition, the path of the Brazil Current, that flows towards Southwest, enhances the drift pattern directed to Southwards. The exceptions appears in Canavieiras and Ilhéus, both on the coast of Bahia, due to the change in the orientation of the coastline, as well as the waves reach the coast from the East.

Already in the coast between Sergipe and Rio Grande do Norte, occurs waves generated by the east Trade winds, without action of waves being promoted by meteorological fronts (Tessler and Goya, 2005), thereby indicating a transport resulting Northwards.

In the location between Cabo de São Roque and Delta do Parnaíba, the action of winds is associated to the east Trade winds, according to Tessler and Goya (2005), which generate waves from East and Northeast. Thus, all sediment transport is directed from East to West, following the Northern Brazil current path.

To conclude the evaluation of the LST at these regions, the temporal cycles of variability can be investigated using wavelet analysis following the methodology proposed by Torrence and Compo (1998) and rectified by Liu et al. (2007) and Veleda et al. (2012).

The following figures show, for five sites (Galinhos - Rio Grande do Norte state, Aracaju Sergipe, Belmonte - Bahia, Saquarema - Rio de Janeiro and Matinhos - Paraná), the time series of LST used for the wavelet analysis, local DOG wavelet power spectrum and the time averaged spectrum.

Figure 2 shows the wavelet analysis at Galinhos, located in Northeastern region. 


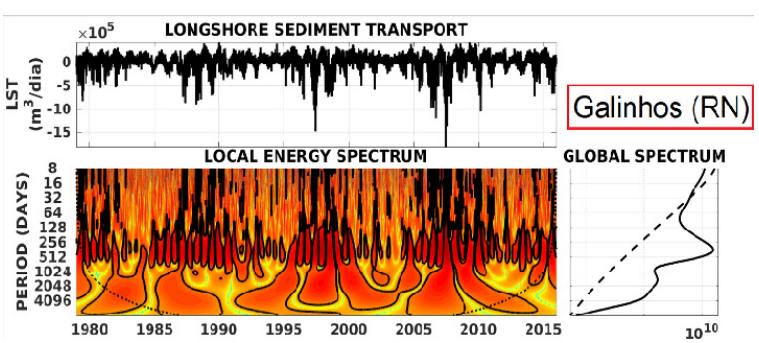

Figure 2. Time series of LST used for the wavelet analysis, Local DOG wavelet power spectrum and the Time Averaged spectrum at Galinhos. Thick contour lines on the power spectrum and gray dashed line at the Time Averaged spectrum enclose regions of greater than $95 \%$ confidence for a red noise process with a lag 1 coefficient of 0.95 .

The time series at Galinhos, Rio Grande do Norte, shows high peaks of LST between 1995 and 2000 and other peaks between 2005 and 2010. The local wavelet spectrum shows the most of energy concentrated within the band of periods from 64 to 512 days, associated with the seasonal and annual cycles. In addition, also occur energy processes for longer periods, associated to climatic phenomena on a global scale, like El Niño Southern Oscillation (ENSO). The high energy associated with these processes is corroborated by the analysis of the global power spectrum of wavelets at Galinhos.

Figure 3 shows the wavelet analysis at Aracaju, located in Northeastern region.

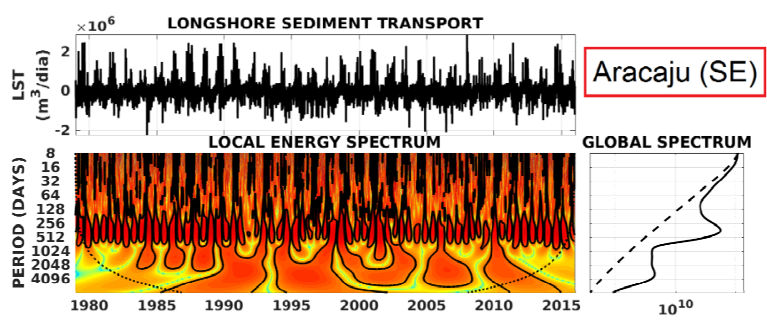

Figure 3. Time series of LST used for the wavelet analysis, Local DOG wavelet power spectrum and the Time Averaged spectrum at Aracaju. Thick contour lines on the power spectrum and gray dashed line at

the Time Averaged spectrum enclose regions of greater than $95 \%$ confidence for a red noise process with a lag 1 coefficient of 0.95 .

In Aracaju, Sergipe, the time series shows high peak of LST between 2005 and 2010. The local wavelet spectrum shows that the most of energy is associated with the seasonal and annual cycles, from 64 to 512 days. In addition, also occur energy processes for longer periods, associated to ENSO. The high energy associated with these processes is corroborated by the analysis of the global power spectrum of wavelets in this site.

Figure 4 shows the wavelet analysis at Belmonte, located in Northeastern region.

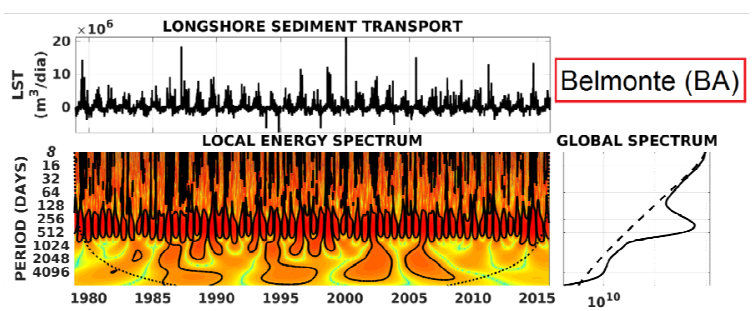

Figure 4. Time series of LST used for the wavelet analysis, Local DOG wavelet power spectrum and the Time Averaged spectrum at Belmonte. Thick contour lines on the power spectrum and gray dashed line at

the Time Averaged spectrum enclose regions of greater than $95 \%$ confidence for a red noise process with a lag 1 coefficient of 0.95 .

For Belmonte, Bahia, the time series shows high peak of LST in the years 1987, 2000 and 2006. The local wavelet spectrum shows that the most of energy in this site is associated with the seasonal and annual cycles, from 64 to 512 days. Also occur energy processes for longer periods, but in a less expressive way. The high energy associated with these processes is corroborated by the analysis of the global power spectrum of wavelets in Belmonte.

Figure 5 shows the wavelet analysis at Saquarema, located in Southeastern region.

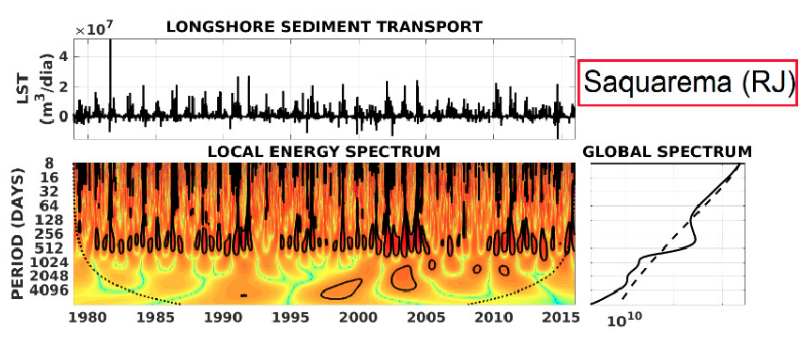

Figure 5. Time series of LST used for the wavelet analysis, Local DOG wavelet power spectrum and the

Time Averaged spectrum at Saquarema. Thick contour lines on the power spectrum and gray dashed line at the Time Averaged spectrum enclose regions of greater than $95 \%$ confidence for a red noise process with a lag 1 coefficient of 0.95 .

The time series at Saquarema, Rio de Janeiro, shows small peaks, having an exception in 1982, where occur a high peak. The local wavelet spectrum shows that the most of energy is associated with the seasonal and annual cycles, from 64 to 512 days. In addition, to shorter cycles, associated with the passage of frontal meteorological systems, and longer periods, the LST does not suffer significant influences. The high energy associated with these processes is corroborated by the analysis of the global power spectrum of wavelets.

Figure 6 shows the wavelet analysis at Matinhos, located in Southern region. 


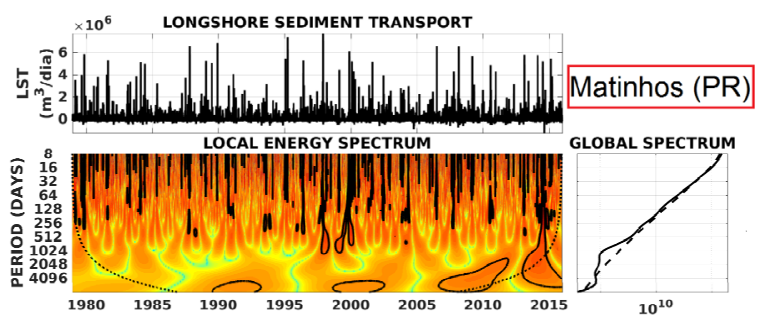

Figure 6. Time series of LST used for the wavelet analysis, Local DOG wavelet power spectrum and the Time Averaged spectrum at Matinhos. Thick contour lines on the power spectrum and gray dashed line at the Time Averaged spectrum enclose regions of greater than $95 \%$ confidence for a red noise process with a lag 1 coefficient of 0.95 .

Lastly, in Matinhos, Paraná, the time series shows high peak of LST between 1995 and 2000. The local wavelet spectrum shows that the seasonal, annual and interannual cycles do not influence directly the LST rates. The analysis of the global power spectrum of wavelets corroborate with this.

\section{CONCLUSION}

From numerical modeling of waves generated by wind it was possible to obtain the parameters of wave in addition to an estimation of the longitudinal transport of sediments (LST). Results of the anual averages obtained from the technique of sectioning the Brazilian coast, followed by trends shown in past studies, resulted in agreement in the order of magnitude and predominant direction of transport.

The results showed a great diversity in the behavior of the wave climate all along the Brazilian coast, which can be verified due to the large difference in means of values of significant wave height, period of peak and average direction of the waves. In this way, it was assumed that the sediment transport along the Brazilian coast also presentes expressive variations, as observed in this study.

The sectors where the rates of LST had become quite pronounced are related to the frame between Alagoas and Rio Grande do Norte, while the smallest on the Southern part of Bahia. The high discrepancy of results is associated to the average diameter of sediments in addition to the steepness of beach profiles, once there is a significant variation along the Brazilian coast. In addition, the methodology considered appropriate for each studied scenario also influenced the results presented, since differences in the littoral drift occur according to the formulation approach used. In this way, it is suggested that in future studies other points are to be considered in the validation of the LST.

The wavelet analysis showed that the spectrum of LST time series has a significant amount of energy for processes with temporal variability from 64 to 512 days, corresponding to the seasonal and annual cycles. It also showed that, as predicted, the action of the winds at short time scales has no influence on the LST rates, since this process requires a long time scale to occur in an effective way.

Nevertheless, the values of the LST obtained in this study were consistent when compared with the results of other authors present in literature, even considering the limitations of the model TOMAWAC. Finally, the present study contributes with state of the art about the behavior of the waves and sediment transport along the Brazilian coast, which can be useful in future engineering projects, involving the management and the sustainable management of the coastal zone.

\section{ACKNOWLEDGEMENTS}

The authors would like to thanks the National Center for Supercomputing (CESUP) - Federal University of Rio Grande do Sul (UFRGS), who helped with the development of this work. Thank you also to the ECMWF by oceanographic and meteorological data used in the model boundary conditions, the consortium Open TELEMACMASCARET by providing the TELEMAC system charge and the National Laboratory of Scientific Computing (LNCC) by making use of the supercomputer Santos Dumont. This study was financed in part by the Coordenação de Aperfeiçoamento de Pessoal de Nivel Superior Brasil (CAPES) - Finance Code 001, and was supported by the Fundação de Amparo à Pesquisa do Estado do Rio Grande do Sul (FAPERGS) under contract 17/2551-001159-7, and by the Conselho Nacional de Desenvolvimento Científico $e$ Tecnológico (CNPq) under the contract 304227/2016-1.

\section{REFERENCES}

Bejan, A., 1995, Convection Heat Transfer, 2nd Edition, Wiley.

Araújo, C. E. S., Franco, D., Melo Filho, E., and Pimenta, F. M., 2003, Wave Regime Characteristics of the Southern Brazilian Coast, in: Sixth International Conference on Coastal and Port Engineering in Developing Countries, XI (097).

Araújo, D. J. C., 2015, Transporte Longitudinal de Sedimento na Zona Costeira de Natal/RN, Doctoral Thesis, Universidade Federal do Rio Grande do Norte. (in Portuguese)

Araújo, R., and Alfredini, P., 2001, O Cálculo do Transporte de Sedimentos Litorâneo: Estudo de Caso das Praias de Suarão e Cibratel (Município de Itanhaém, São Paulo), Revista Brasileira de Recursos Hídricos, Vol. 6, No. 2, pp. 15-28.

CERC, 1984, Shore Protection Manual, U.S. Army Coastal Engineering Research Center.

Contestabile, P., Ferrante, V., and Vicinanza, D., 2015, Wave Energy Resource along the Coast of Santa Catarina (Brazil), Energies, Vol. 8, No. 12, pp. 


\section{9-14243.}

del Valle, R., Medina, R., and Losada, M. A., 1993, Dependence of Coefficient K on Grain Size, Journal of Waterway, Port, Coastal, and Ocean Engineering, Vol. 119, No. 5, pp. 568-574.

Hallak, R., and Pereira, A. J., 2011, Metodologia para Análise de Desempenho de Simulações de Sistemas Convectivos na Região Metropolitana de São Paulo com o Modelo ARPS: Sensibilidade a Variações com os Esquemas de Advecção e Assimilação de Dados, Revista Brasileira de Meteorologia, Vol. 26, No. 4, pp. 591-608. (in Portuguese)

Holthuijsen, L. H., 2007, Waves in Oceanic and Coastal Waters, Cambridge University Press.

Kamphuis, J. W., 1991, Alongshore Sediment Transport Rate, Journal of Waterway, Port, Coastal, and Ocean Engineering, Vol. 117, No. 6, pp. 624.

Kamphuis, J. W., Davies, M. H., Nairn, R. B., and Sayao, O. J., 1986, Calculation of Litoral Sand Transport Rate, Coastal Engineering, Vol. 10, No. 1, pp. 1-21.

Klein, A. H. D. F., Menezes, J. T., Diehl, F. L., de Abreu, J. G. N., Polette, M., Sperb, R. M., and Horn, N., 2006, Santa Catarina, in: Erosão $e$ Progradação do Litoral Brasileiro Litoral Brasileiro, Ministério do Meio Ambiente (MMA), Brasília, pp. 401-436. (in Portuguese)

Liu, Y., Liang, X. S., and Weisberg, R. H., 2007, Rectification of the Bias in the Wavelet Power Spectrum, Journal of Atmosferic and Oceanic Technology, Vol. 24, No. 1, pp. 2093-2102.

Marcelino, A. M. T., Pinheiro, L. R. d. S. G., and Costa, J. R. S., 2018, Planejamento Participativo para a Gestão da Orla Marítima de Galinhos/RN, Nordeste Brasileiro, com Apoio de Sensores Remotos e Modelagem Costeira, Revista Desenvolvimento e Meio Ambiente, Vol. 44, No. 1, pp. 118-139. (in Portuguese)

Mil-Homens, J., Ranasinghe, R., van Thiel de Vries, J. S. M., and Stive, M. J. F., 2013, Reevaluation and Improvement of Three Commonly Used Bulk Longshore Sediment Transport Formulas, Coastal Engineering, Vol. 75, No. 1, pp. 29-39.

Muehe, D., and Corrêa, C. H. T., 1989, The Coastline between Rio de Janeiro and Cabo Frio, in: Coastlines of Brazil, American Society of Civil Engineers, pp. 110-123.

Oleinik, P. H., Marques, W. C., and Kirinus, E. d. P., 2017, Evaluation of the Seasonal Pattern of Wind-Driven Waves on the South-Southeastern Brazilian Shelf, Defect and Diffusion Forum, Vol. 370, No. 1, pp. 141-151.

Pianca, C., Mazzini, P. L. F., and Siegle, E., 2010, Brazilian Offshore Wave Climate based on NWW3 Reanalysis, Brazilian Journal of Oceanography, Vol. 58, No. 1, pp. 53-70.

Silva, A., Leitão, J., Dias, A., Coli, A., Fachin, S., and Lontra, G., 2000, Evaluation of Sediment
Transport Processes in the Port of Fortaleza - Brazil, in: International Conference on Coastal Engineering, pp. 3742-3754.

Teegavarapu, R. S. V., 2012, Floods in a Changing Climate: Extreme Precipitation, Cambridge University Press.

Tessler, M. G., and Goya, S. C., 2005, Processos Costeiros Condicionantes do Litoral Brasileiro, Revista do Departamento de Geografia, Vol. 17, No. 1, pp. 11-23. (in Portuguese)

Torrence, C., and Compo, G. P., 1998, A Practical Guide to Wavelet Analysis, American Meteorological Society, Vol. 79, No. 1, pp. 61-78.

Veleda, D., Montage, R., and Araujo, M., 2012, Cross-Wavelet Bias Corrected by Normalizing Scales, Journal of Atmosferic and Oceanic Technology, Vol. 29, No. 1, pp. 1401-1408. 